\title{
Development of an objective method for the comparison of fired projectiles using an air pistol as a template
}

\author{
Noor Hazfalinda Hamzah a,b \\ ${ }^{a}$ Forensic Science Program, Faculty of Health Sciences, Universiti Kebangsaan Malaysia, Jalan Raja \\ Muda Abdul Aziz, 50300 Kuala Lumpur, Malaysia \\ ${ }^{\mathrm{b}}$ Centre for Forensic Science, Department of Pure and Applied Chemistry, The University of \\ Strathclyde, Royal College Building, 204 George Street, G1 1XW Glasgow, United Kingdom
}

This is peer-reviewed accepted author manuscript of the following publication:

Hamzah, N. H. (2016). Development of an objective method for the comparison of fired projectiles using an air pistol as a template. Forensic Science International, 264, 106-112. 10.1016/j.forsciint.2016.03.050 


\begin{abstract}
The ability to objectify ballistic evidence is a challenge faced by firearms examiners around the world. A number of researchers are trying to improve bullet-identification systems to address deficiencies detailed within the National Academy of Science report (2009). More recently focus has turned to making use of more sophisticated imaging modalities to view entire regions of the projectile and the development of automated systems for the comparison of the topographical surfaces recorded. Projectiles from a newly bought air pistol with .177 calibre pellets (unjacketed), fired series of 609 pellets were examined using an optical microscope. A mathematical methodology was developed to pre-process the resultant topographical maps generating point data for comparison, analysed using the Principal Component Analysis (PCA). In most cases limited to reasonable success was achieved. The objective method still requires an operator to identify the Land Engraved Areas to be scanned, however the mathematical alignments were objectively achieved. The PCA results illustrated that the striation marks were not exclusive nor specific to the LEA regions but rather crossed over regions. This study also proves that a single weapon does not necessarily leave identical marks of projectiles on its surface.
\end{abstract}

Keywords: surface topography measurements, bullet-identification system, unjacketed bullets, air weapon, pellets, principal component analysis, acquired characteristics

\title{
1. Introduction
}

Firearm identification has evolved from visual comparison with the conventional comparison microscope [1] or advanced optical or confocal microscope [2] to the introduction of automated and computerised striation evaluation using surface topography measurements [3, 4]. There is a need to address the current largely subjective approach to the observation and interpretation of striation marks [5, 6] and move to more objective methods. An objective approach to the matching of striation marks would also provide a means of addressing challenges to the robustness and scientific basis of ballistic evidence which may increasingly arise from legal challenges [5].

Various systems for objectifying the matching striations, including the use of 3D optical microscopes have been developed. This chapter explores the use of such an approach to examine whether the striated marks or the acquired characteristics [7] present within each 
land engraved areas (LEA) on different pellets (unjacketed) repetitively fired by the same air pistol could be associated with each other using mathematical methods.

\section{Materials and Methodology}

A Weihrauch model HW 45 (Figure 1), 12 right rifling, spring-piston air pistol, was purchased new and had only been fired as part of the manufacturers' tests during production accounting for less than 10 fired pellets. The air pistol was $278 \mathrm{~mm}$ in length, with barrel length of $170 \mathrm{~mm}[8,9]$ and weighed $1.15 \mathrm{~kg}$. RWS® Superdome $4.5 \mathrm{~mm}(.177 \mathrm{cal})$, round nosed unjacketed pellets (Figure 2), were used throughout the project. Each pellet weighed 8.3 grains. These are waisted Diabolo pellets which are described as a soft-lead ammunition and are noted as the pellet of choice for air pistols [10] and for target shooting [11, 12].

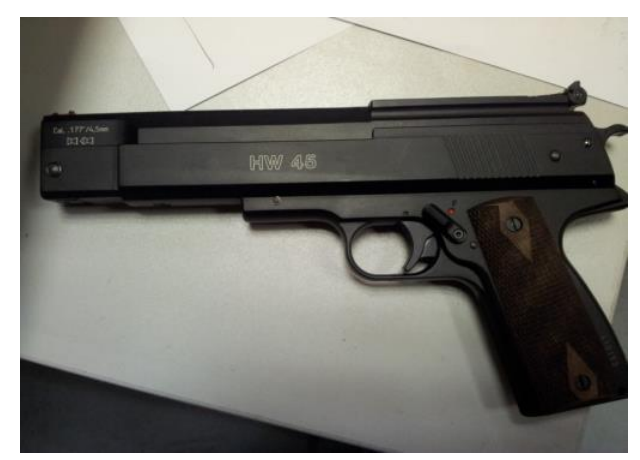

Figure 1: A Weihrauch model HW 45 air pistol

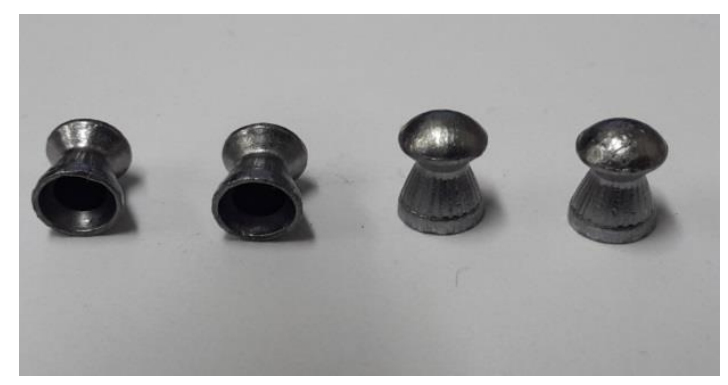

Figure 2: RWS® Superdome $4.5 \mathrm{~mm}(.177 \mathrm{cal})$, round nosed pellets, weight 8.3 grains, unjacketed

A series of shooting was done between April 2012 to September 2013. 50 pellets (numbered 159 to 208), collected in April 2013 were analysed using the Alicona ${ }^{\circledR}$ infinite focus microscope. In each case the 12 LEA regions, labelled A through to L, were landscaped and scrutinised to develop the mathematical processing tools using Matlab® R2014a with PLS_Toolbox $®$ software. 


\subsection{Image acquisition}

All 50 pellets were scanned with Alicona ${ }^{\circledR}$, an optical microscope capable of producing a 3D image. It is highly accurate for automatic 3D micro coordinated and surface roughness measurements [13]. The head of the pellet was placed in the holder and attached using Blu$\mathrm{Tac}^{\mathrm{TM}}$ so that the skirt area or the bottom most part of the pellet was oriented to face the microscope user. The pellet was positioned so that the target LEA was directly below the lighting source and perpendicular to the lens of the microscope. The identification of the LEAs was initially undertaken under the supervision of an experienced ballistics expert so that these regions could be identified with confidence.

The platform holding the pellet could be moved along the $\mathrm{x}, \mathrm{y}$ and $\mathrm{z}$ axis in order for the microscope to scan and measure the surface of the regions of interest. The image produced was in $3 \mathrm{D}$ format. The best-captured surface which contained details of the striations on the surface of the pellet was selected in each case. Once the image of the striated region was captured using the microscope, a line was drawn across the LEA using the software associated with the instrument (Figure 3). The red line from point A to point B represents the distance of one LEA from a pellet drawn onto the image using the software.

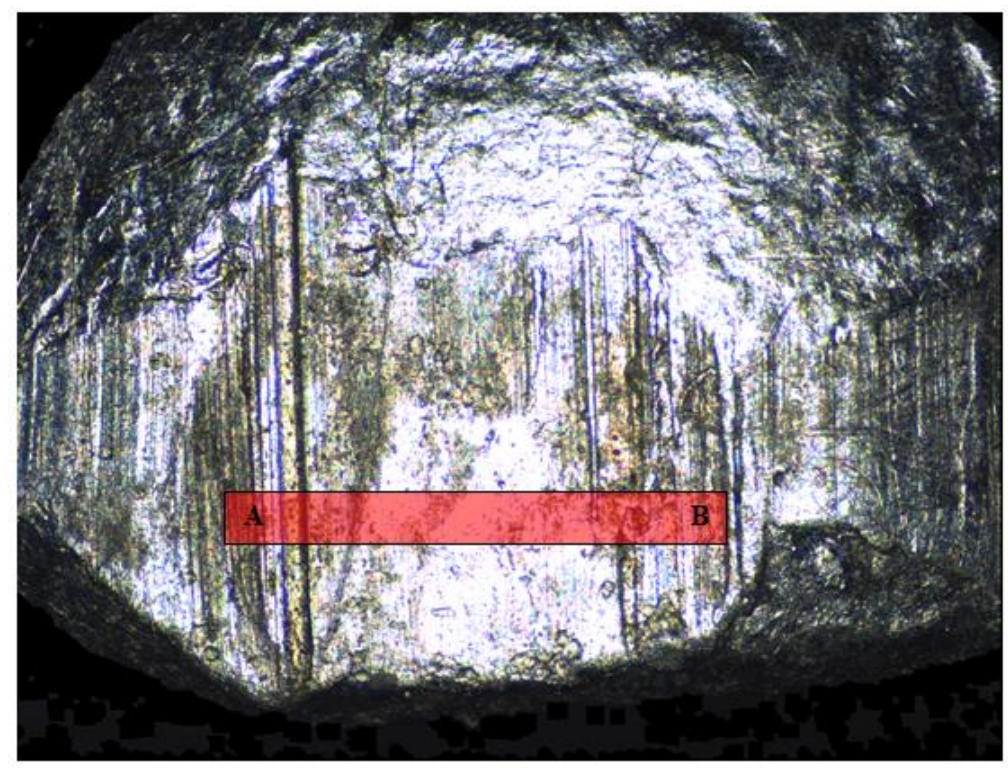

Figure 3: A 2D image generated from the Alicona ${ }^{\circledR}$ showing a LEA on a pellet. The length of the LEA is measured from $A$ to $B$. The identification of the LEA was under the supervision of an experienced ballistics expert who determine the edge of each LEA 
After scanning, the image of the LEA was displayed on the computer monitor. The Alicona ${ }^{\circledR}$ comes with its own software for length measurement. Primary profile measurement was selected, as recommended by the British Standards Institution [14-17]. The borders of the LEA were selected and the Alicona ${ }^{\circledR}$ software transformed the LEA striation image such that the surface topography of the pellet was displayed as a graph post measurement, as shown in Figure 4 . The surface measurement graph contains numerical values which indicate the depth or the surface topography of the striation. Each point in the graph corresponds to a valley or peak of the pellet surface. The numerical values were then selected for image transformation using Matlab® R2014a with PLS_Toolbox® software.

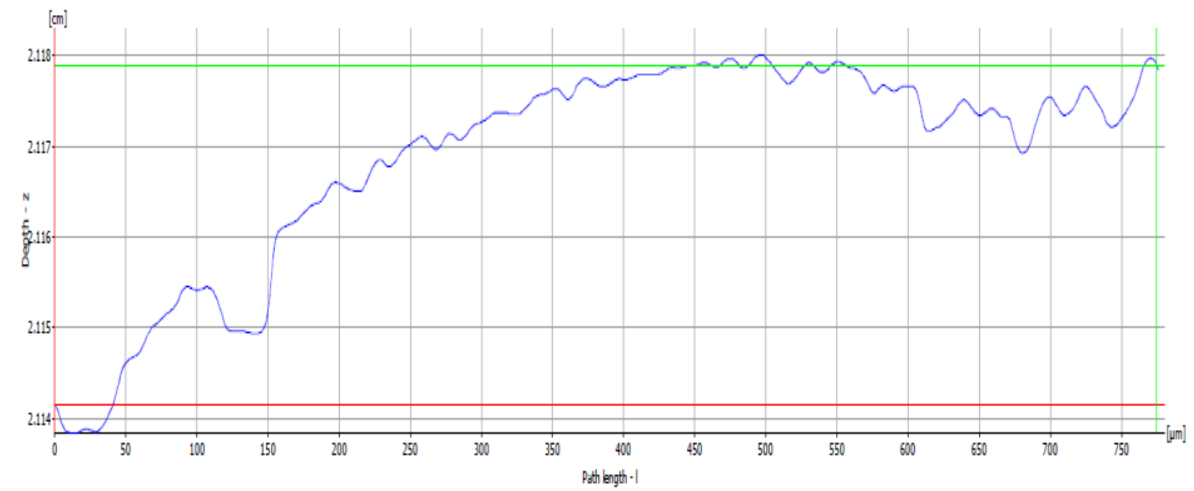

Figure 4: Graph of surface topography of LEA A, pellet 161, along the length of the LEA

\subsection{Data transformation and image alignment}

All numerical data was selected from the topographical graphs required further data processing so that analysis and comparisons could be undertaken. This was carried out using a curve flattening script followed by an image alignment script. The resultant data set was then subjected to the principal component analysis (PCA).

\section{Curve flattening}

Curve flattening of the topographical maps associated with the LEA using a polynomial curve fit was undertaken. Curve removal and alignment was needed before analysis of the data so that measurement error was minimised. Figure 5 is a close up for a set of three measurements of LEA A on the same pellet where the topographical maps are aligned. A curve removal script from Matlab® was used to flatten the curve across the topographical map so that all of the data from repetitive measurements $(n=3)$ across each LEA on each pellet could be aligned for comparison. 


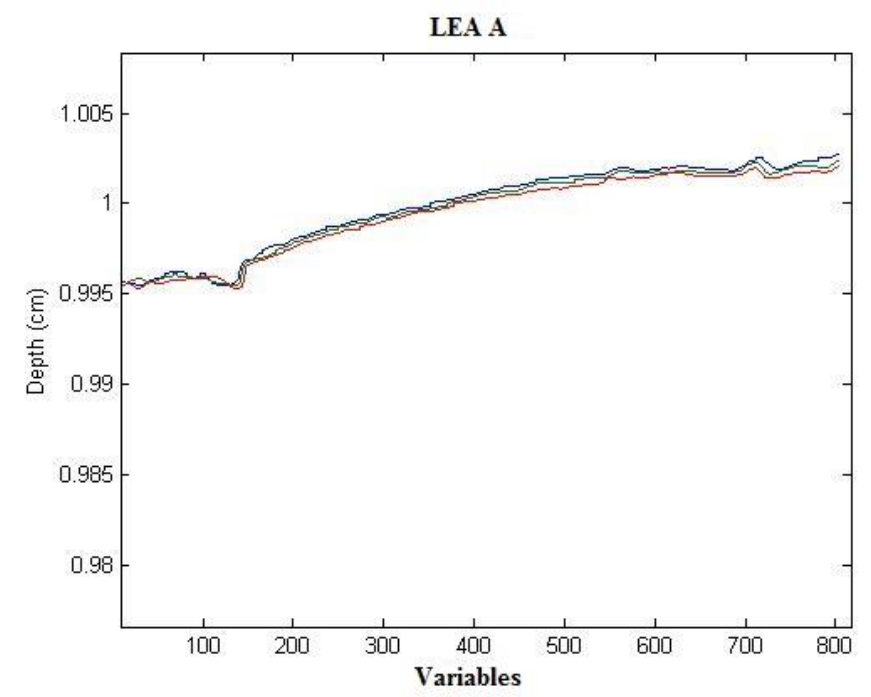

Figure 5: This is a close up of one of the three repeat surface measurements for LEA A

Figure 6 is the close up of two measurements from two pellets after the curve was removed. There are two sharp features from pellet 159 and pellet 162 . For pellet 159 , the valley feature is between variable number 100 and 200; for pellet 162, the valley feature is just before variable number 100. These sharp features are similar but mismatched. A cross correlation function was used to align both features.

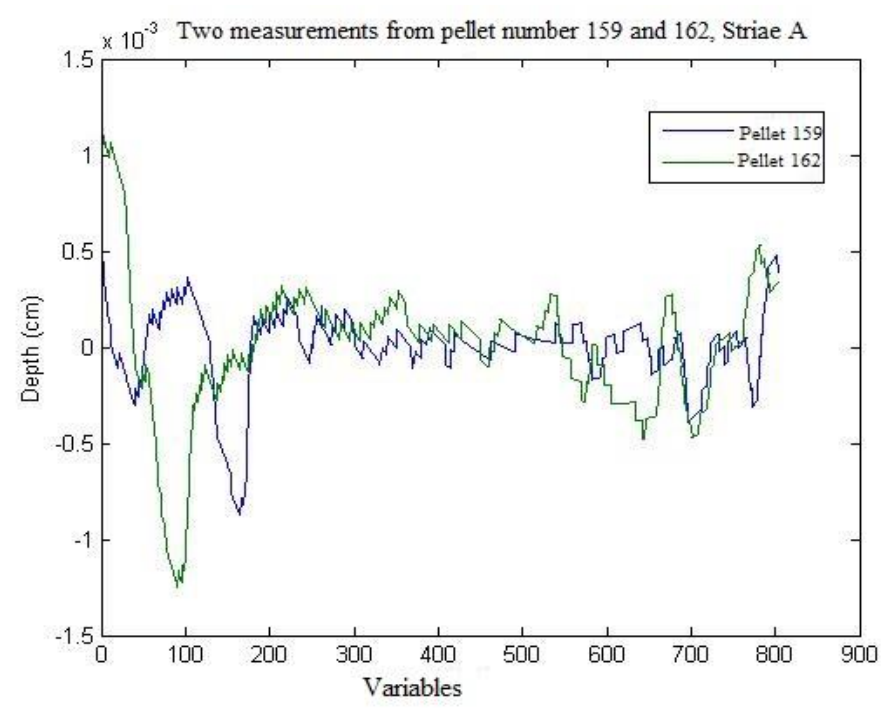

Figure 6: This is an example of polynomial curve fitting of measurements of LEAs from two pellets (pellet 159 and pellet 162), LEA A. Both graphs are similar; however, alignment is needed before comparison of the striated marks is effective 
Figure 7 illustrate this process applied across 3 repetitive measurements of LEA A measured for 50 pellets. Figure 8 shows the alignment of all 150 measurements for LEA A ( 3 repetitive measurements of LEA A across 50 separate pellets) after the alignment script was applied to data in Figure 7.

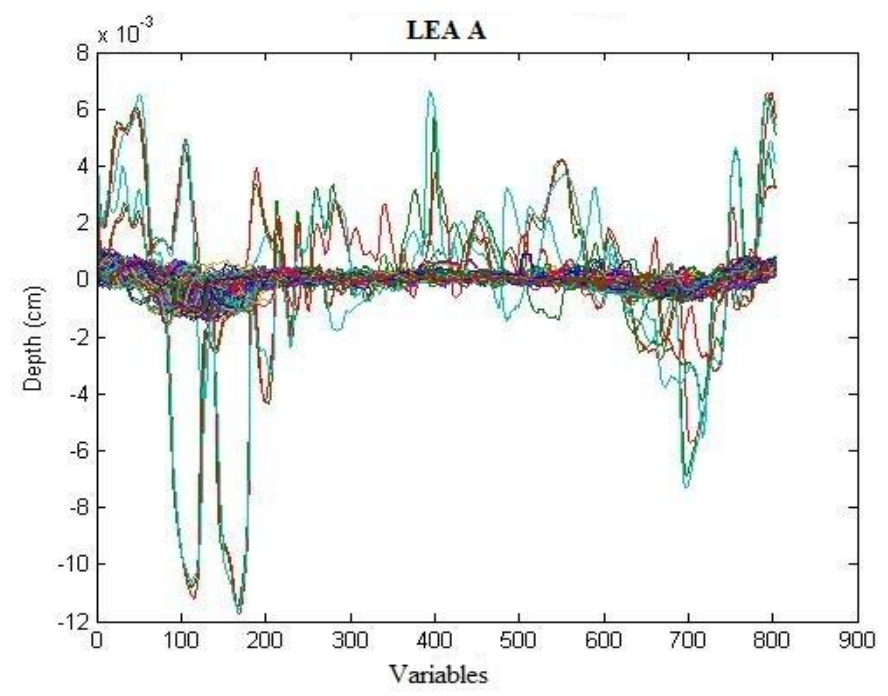

Figure 7: This is an example of removal of curve from LEA A (150 measurements of striations - three repetitive measurements of the region across 50 pellets). The original surface topography, as in Figure 4, was fitted with a polynomial curve before alignment

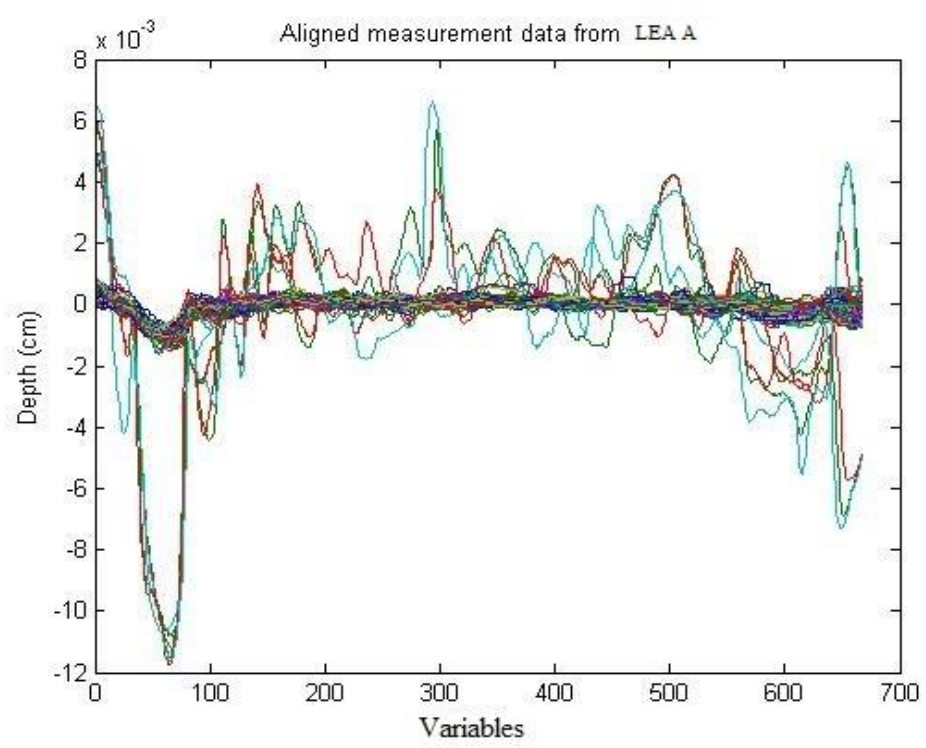

Figure 8: Aligned measurements of LEA A (150 measurements of surface topography). The sharp features are now aligned and this data is ready to be analysed using the PCA

The difference between the unaligned data in Figure 7 and aligned data in Figure 8 are highlighted in Figure 9 with the misaligned graph labelled (A) and the aligned one (B). The 
cross correlation function moves the signals on top of each other facilitating the analysis of correlation between groups of data.
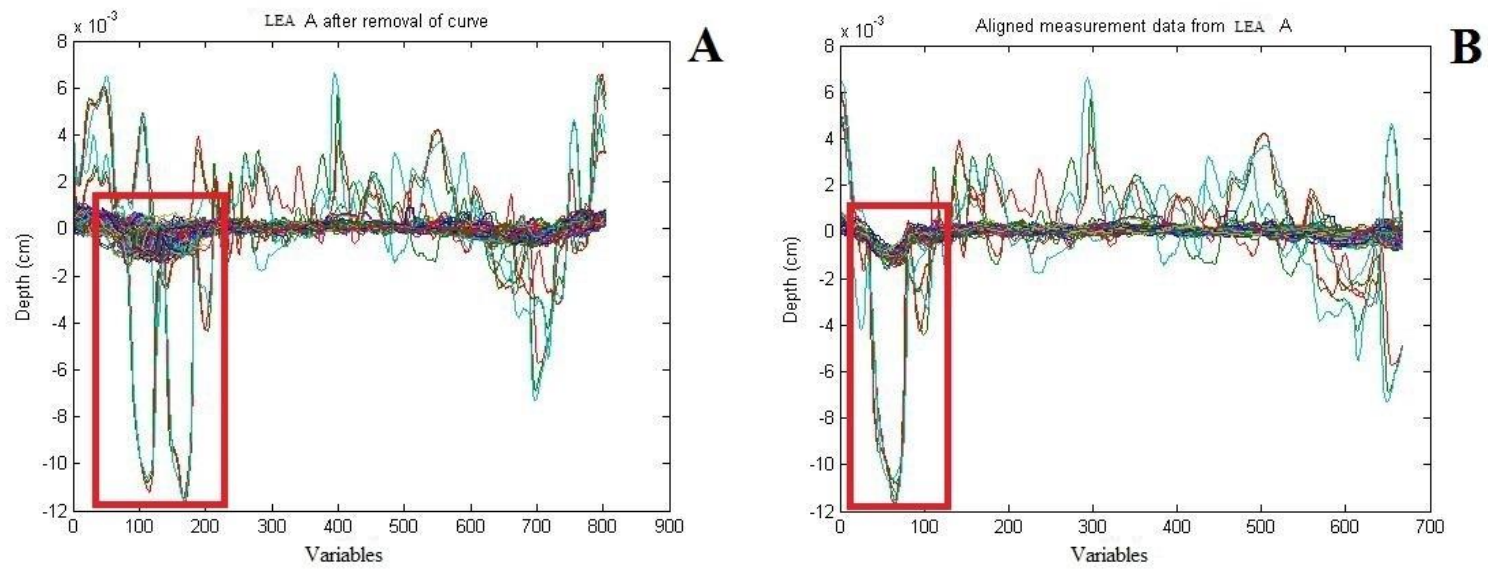

Figure 9: The sharp features highlighted by the red rectangle before $(A)$ and after $(B)$ alignment using the cross correlation function from Matlab®

In summary, the scanned images of the LEAs from the pellets were transformed into a set of numerical data. This data were then pre-processed by removing the curve followed by data aligning using Matlab®. All measurements were aligned to the first measurement of pellet number 159 . The aligned data were then analysed using the PCA.

\section{Results and discussion}

All 12 LEAs for each of the 50 pellets were scanned, with the exception of the surface area of LEA $F$ on pellets numbered 177 and 178, where the degree of surface corrosion meant that imaging would not yield results of sufficient quality for comparison and LEA L on pellet number 161 which bore an additional mark.

In total, 1416 measurements were aligned out of a possible 1791 taken from 597 scanned images. Corrosion of the LEA surface resulting obscuring or distorting the striation marks was the main reason for misalignment; however, other factors contributed, such as the presence of additional marks on the surface of the pellet or flattening of the pellets also affected alignment. Precautions were taken during this research, to carefully dry the pellets before storage in polythene bags, and careful handling of the pellets however, some of the pellets were still subject to corrosion and damage. Other factors which may have influenced 
the reproducibility of the striation marks observed was undoubtly the cleanliness of the weapon as suggested by Burd and Kirk [1]. A summary of this data is presented in Table 1.

Table 1: Summary of aligned measurements for LEA A to LEA L

\begin{tabular}{|c|c|c|c|c|}
\hline LEA & $\begin{array}{c}\text { Number of pellets } \\
\text { scanned }\end{array}$ & $\begin{array}{c}\text { Number of } \\
\text { measurements for } \\
\text { alignment }\end{array}$ & $\begin{array}{c}\text { Number of } \\
\text { aligned } \\
\text { measurements }\end{array}$ & $\begin{array}{c}\text { Percentage of } \\
\text { aligned } \\
\text { measurements } \\
(\%)\end{array}$ \\
\hline A & 50 & 150 & 147 & 98 \\
\hline B & 50 & 150 & 120 & 80 \\
\hline C & 50 & 150 & 114 & 76 \\
\hline D & 50 & 150 & 144 & 96 \\
\hline E & 50 & 150 & 78 & 62 \\
\hline F & 48 & 144 & 90 & 70 \\
\hline G & 50 & 150 & 105 & 100 \\
\hline H & 50 & 150 & 72 & 100 \\
\hline I & 50 & 150 & 150 & 96 \\
\hline J & 50 & 150 & 144 & 65 \\
\hline K & 50 & 150 & 96 & 78 \\
\hline L & 49 & 147 & 1410 & \\
\hline Total & 597 & 1791 & & \\
\hline
\end{tabular}

The data derived from the aligned topographical maps presented a set of variables for each striated region which could be subject to mathematical methods in order that pattern matching could be undertaken. This would provide an objective mathematical method to evaluate the linkage between the different striated regions of interest (the LEA regions) on bullets of known origin.

The PCA was undertaken using Matlab® and three data sets were originally chosen depending on the percentage of aligned measurements within the data representing the various LEA at $90 \%, 70 \%$ and $50 \%$ alignment.

Based on Table 1, below are the groupings of LEAs which were considered;

- more than $50 \%$ of measurements aligned - LEA A, B, C, D, E, F, G, H, J, K, L

- more than $70 \%$ of measurements aligned - LEA A, B, C, D, G, H, J, K

- more than $90 \%$ of measurements aligned - LEA A, D, H, J, K

LEA I was not included in the PCA because of the lower than $50 \%$ of aligned measurements. 
Figure 10 reveals the PCA result for all LEAs except for LEA I. These LEAs are presented at $50 \%$ alignment or greater across the striated regions. LEA D is the only region that remains well defined and differentiated from all others.

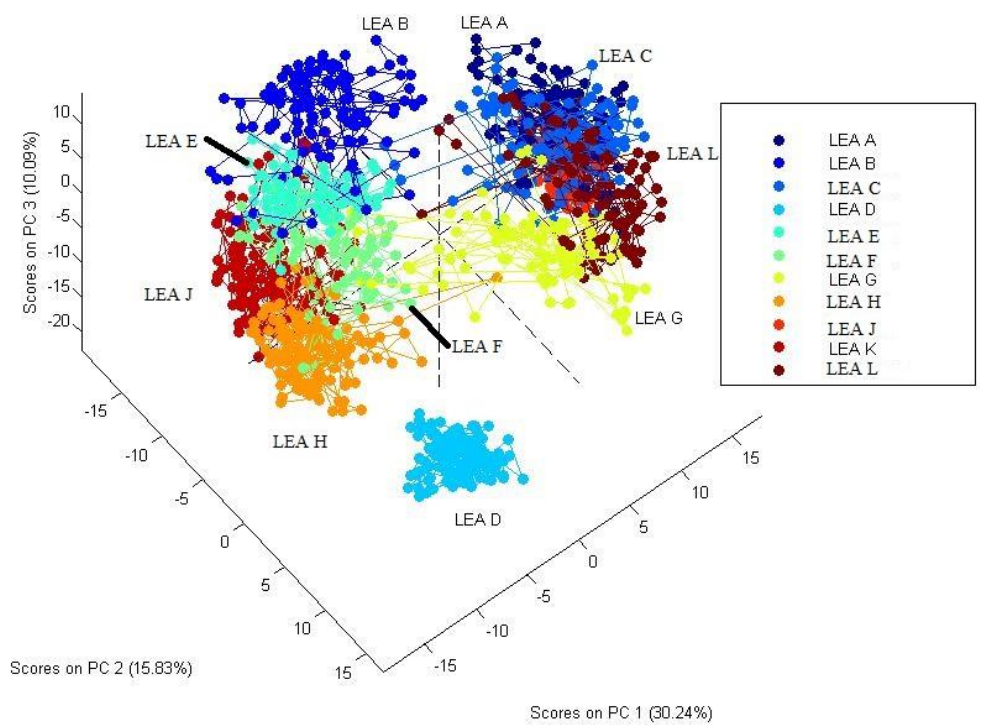

Figure 10: The PCA results for the more than 50\% aligned measurements of LEAs

Visually, LEA B, C, E, F, G, H, K and L all look similar with no acquired characteristic marks on their surface. Figure 11 illustrates all these LEAs.

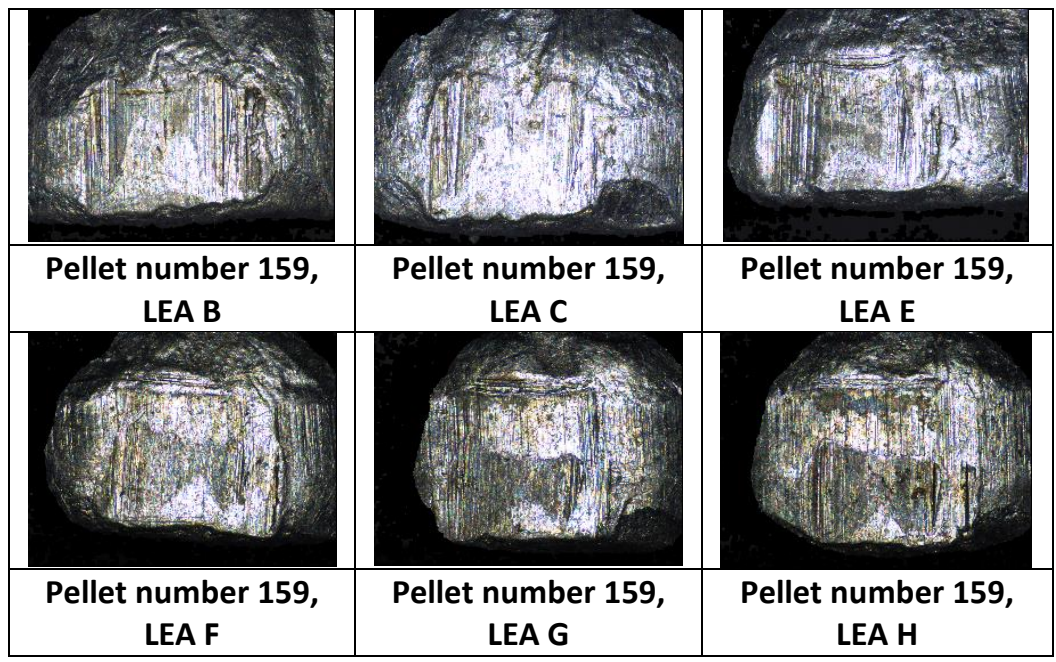




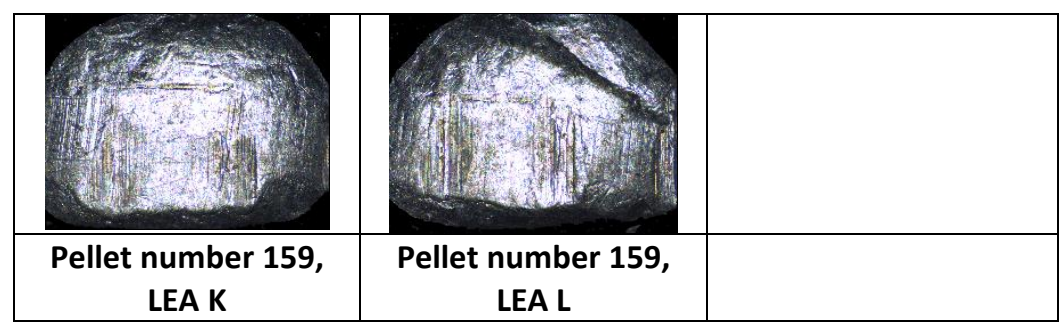

Figure 11: The scanned image of pellet number 159, LEA B, C, E, F, G, H, K and L

The PCA results illustrate quite clearly that as the threshold for alignment across an LEA is reduced the LEA convolute providing little discrimination across these regions of interest.

Figure 12 reveals the PCA results of more than $70 \%$ aligned measurements of LEAs A, B, C, D, G, H, J. All LEAs were poorly differentiated from each other except for LEA D. Visually; LEA B, C, G, H and $\mathrm{K}$ look similar to each other and this is illustrated in Figure 11. Even though LEA A and J have acquired characteristics marks, these are not sufficient to clearly differentiate these from other LEAs (B, C and $\mathrm{G})$ at only $70 \%$ alignment of the striations.

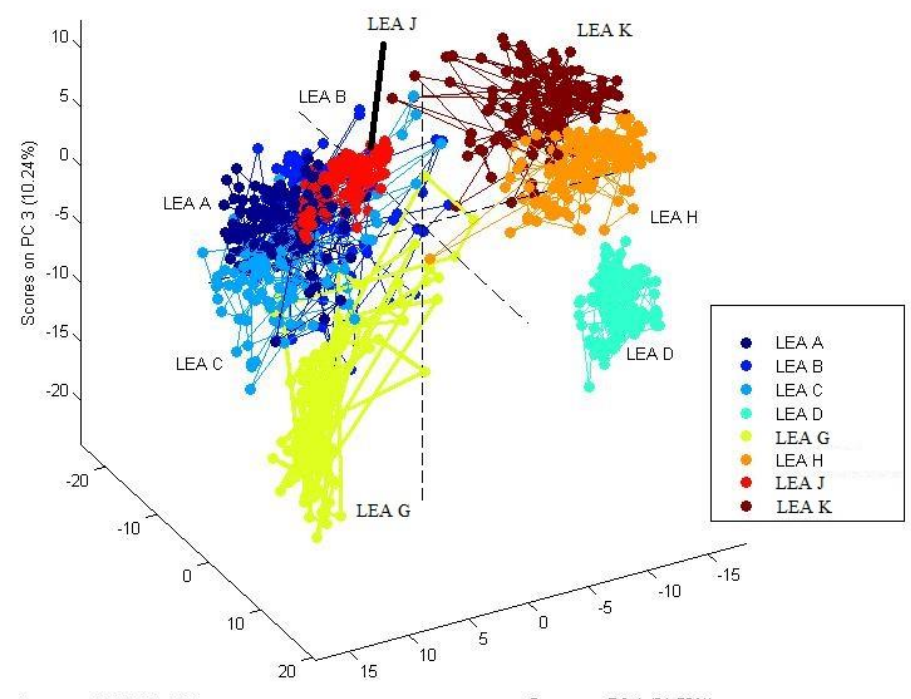

Scores on PC $2(16.14 \%)$

Scores on PC $1(31.58 \%$

Figure 12: The PCA results for the more than $70 \%$ aligned measurements of LEAs 
Figure 13 shows the PCA results derived from the LEA where $90 \%$ or better alignment of the topographical maps was achieved.

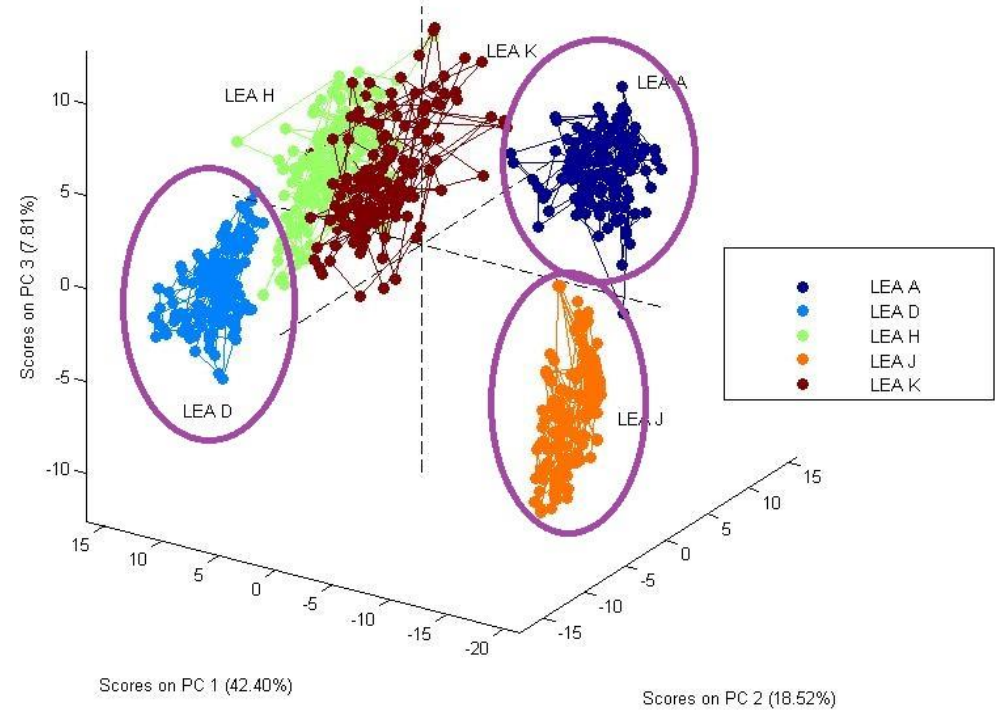

Figure 13: The PCA results for the more than $90 \%$ aligned measurements of LEAs

At $90 \%$ alignment of the striation marks, LEA A, D and $\mathrm{J}$ are well defined and separated from the convoluted group of LEA K and H, as in the purple circle. Figure 14 presents the scanned images of, LEA A, D, H, J and $\mathrm{K}$ on pellet number 159 by way of an example. Visually, LEA A, D and J contain a set of acquired characteristics marks different from LEA $\mathrm{H}$ and $\mathrm{K}$. This is probably the reason for the separation of these three LEAs.

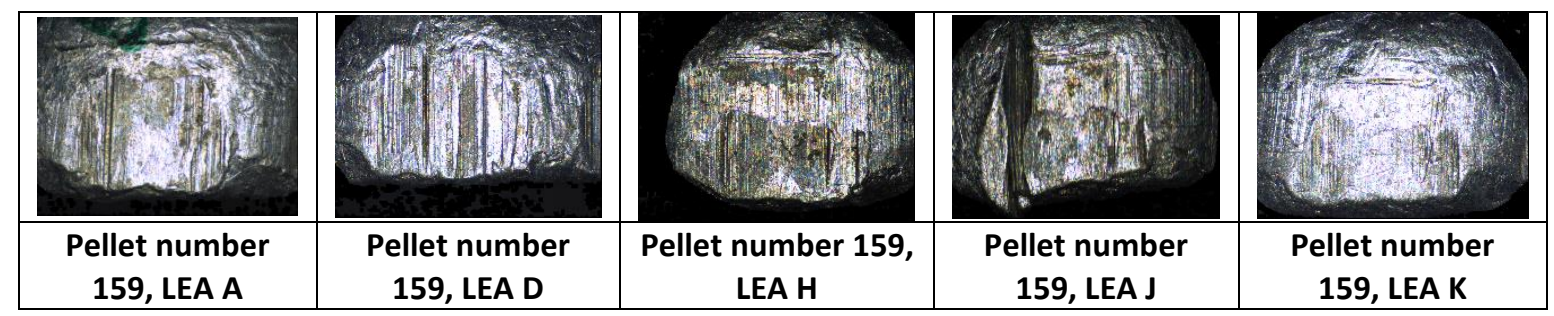

Figure 14: The scanned image of pellet number 159, LEA A, D, H, J and K. Visually, LEA A, D and J have distinct acquired characteristic marks on its surface which make them different from LEA $H$ and $K$ 


\section{Conclusion}

Burd and Kirk's suggested that that a single weapon does not necessarily leave identical marks of projectiles and this study has corroborated this. Through the use of a 3D scanning microscope, 2D images were pre-processed and aligned for further analysis. This facilitated accurate measurement of the surface of each pellet and the outputted surface topography was used for a comparison.

The choice of the LEAs required some experience, however the instrument delivered reproducible results across the chosen region and once the numerical data has been retrieved using the Alicona ${ }^{\circledR}$ software, the pre-processing, alignment and analysis of the data are all done automatically using computerised software. While other researchers have created new algorithms, software or tools for the purpose of objectifying ballistic evidence, this research suggests that striations can be objectified and meaningful results produced by using an optical microscope with software which can measure the surface topography of the pellets, as well as Matlab® with PLS_Toolbox®.

Corrosion of the pellet surface was a limiting factor in terms of choice of LEA available to alignment. In occasional cases, extra marks were also in evidence on the pellet surfaces.

The PCA results of eleven LEAs, illustrated that the striation marks were not exclusive nor specific to the LEA regions but rather crossed over regions. As the degree of alignment of the striation marks is increased the convolution of the LEA regions decreases however it is not completely resolved. Given that such discrimination is critical to the process, only LEAs where $90 \%$ or better alignment across repetitive measurements can be recommended.

\section{References}

1. Burd, D.Q. and Kirk, P.L., Tool Marks. Factors Involved in Their Comparison and Use as Evidence. Journal of Criminal Law and Criminology (1931-1951), 1942. 32(6): p. 679-686.

2. Banno, A., Masuda, T. and Ikeuchi, K., Three dimensional visualization and comparison of impressions on fired bullets. Forensic Science International, 2004. 140(2-3): p. 233-240.

3. John, S., Wei, C., Mingsi, T. and Johannes, S., 3D topography measurements on correlation cells-a new approach to forensic ballistics identifications. Measurement Science and Technology, 2014. 25(6): p. 064005.

4. Zheng, X., Soons, J., Vorburger, T., Song, J., Renegar, T. and Thompson, R., Applications of surface metrology in firearm identification. Surface Topography: Metrology and Properties, 2014. 2(1): p. 1-10. 
5. Committee on Identifying the Needs of the Forensic Sciences Community, N.R.C., Strengthening Forensic Science in the United States: A Path Forward. 2009: National Academies Press.

6. Margot, P. Commentary on the Need for a Research Culture in the Forensic Sciences. 2011. UCLA L. Rev. 58: 795-801

7. Meuwly, D., Veldhuis, R. Forensic Biometrics: From two communities to One Discipline. International Conference of the Biometrics Special Interest Group - (BIOSIG). 2012, A. Brömme and C. Busch. Darmstadt, Germany, Gesellschaft für Informatiek e. V. (G.I.). 196: $207-218$

8. Air, P. Weihrauch Guns. 2012 [cited 2014; Available from: http://www.pyramydair.com/manual/hw45.

9. Weihrauch, H.-H. and Weihrauch, S. Weihrauch Sport - Air Pistols. 2012 [cited [2014]; Available from: http://www.weihrauchsport.de/seiten/englisch/luftpistolen/e luftpistolen.html\#TD Luftpistolen d.

10. Di Maio, V.J.M., Gunshot wounds : practical aspects of firearms, ballistics, and forensic techniques. 1999: Boca Raton : CRC Press.

11. Saltzman, B. American Airguns. 2006 [cited 2014; Available from: http://www.airguns.net/general airgun types.php.

12. Gaylor, T., The right pellet makes a difference. Airgun Revue \#1. Vol. \#1. 1997: GAPP, Inc.

13. Alicona. Alicona Infinite Focus. 2013 [cited 2014; Available from: http://www.alicona.co.uk/home/products/infinitefocus.html.

14. Tdw, Geometrical product specification (GPS). Surface texture. Profile method. Motif parameters. Geometrische Produktspezifikationen (GPS). Oberflächenbeschaffenheit. Tastschnittverfahren. Motifkenngrößen. 1997.

15. Tdw, Geometric product specification (GPS). Surface texture. Profile method: Rules and procedures for the assessment of surface texture. Geometrische Produktspezifikation (GPS). Oberflaechenbeschaffenheit. Tastschnittverfahren. Regeln und Verfahren fuer die Beurteilung der Oberflaechenbeschaffenheit. 1997.

16. Tdw, Geometrical product specification (GPS). Surface texture: Profile method. Terms, definitions and surface texture parameters. Geometrische Produktspezifikation (GPS). Oberflächenbeschaffenheit. Tastschnittverfahren. Benennungen, Definitionen und Kenngrößen der Oberflächenbeschaffenheit. 2000.

17. Tdw, Geometrical product specifications (GPS). Surface texture. Areal. Terms, definitions and surface texture parameters. Geometrische Produktspezifikation (GPS). Oberflächenbeschaffenheit. Flächenhaft. Begriffe und Oberflächen-Kenngrößen. 2012. 